
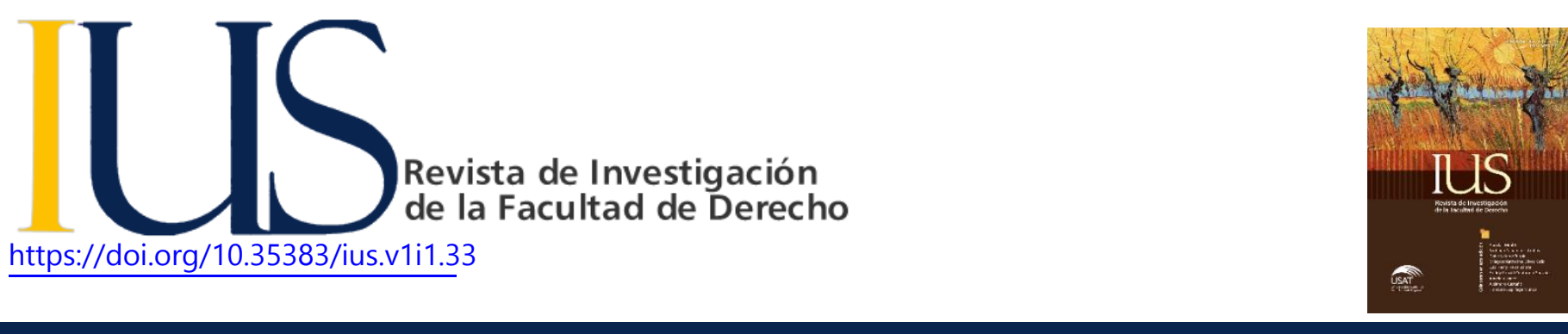

\title{
EL MARCO JURÍDICO DE LA MIGRACIÓN EN MARRUECOS
}

\section{Abdelali Mrabti 1}

\section{INFORMACIÓN DEL ARTÍCULO}

\section{Historia del artículo:}

Recibido el 01 de octubre de 2018

Aceptado el 31 de mayo de 2019

\section{Palabras claves:}

Marruecos

Regularización

Emigrantes

Inmigrantes

\section{RESUMEN}

A lo largo de la historia, Marruecos se formó a través de una mezcla diversa de las poblaciones de diferentes orígenes, alimentada por sucesivas migraciones, en particular de países con los que este Estado tiene relaciones especiales y antiguas (Francia, España, Argelia o Senegal). Situado en el extremo noroeste del continente africano, Marruecos tiene una localización estratégica en el Mediterráneo como puente entre África y Europa. Su historia como país de emigración es larga, aunque el auge de los flujos de salida se produce en la década de los años sesenta. En la actualidad Marruecos es una encrucijada fundamental de las corrientes migratorias que se dirigen hacia Europa y el principal país de emigración de la orilla Sur del Mediterráneo. Marruecos se convirtió en un país de tránsito y de destino para muchos migrantes de África del Occidental, muchos de los cuales son irregulares.

\section{THE LEGAL FRAMEWORK OF MIGRATION IN MOROCCO}

\section{ABSTRACT}

\section{Keywords.}

Morocco

Immigrants

Emigrants
Throughout history, Morocco was formed by a diverse mix of populations of different origins, and this was a result of successive migrations, in particular from countries which have a special and ancient relation with morocco such as (France, Spain, Algeria and Senegal). Morocco is situated on the extreme northwestern corner of Africa. Thus, it has two coastlines, the Pacific Ocean and the Mediterranean. Thanks to its geographical location, Morocco can act as a bridge between Africa and Europe. Historically, morocco is known as a country of emigration. And although the outflows occurred in the sixties, morocco has evolved and became an important crossing point for migrants to Europe. Also it represents the main emigration country on the southern shores of the Mediterranean especially for many West Africa migrants that many of them are illegal.

\footnotetext{
${ }^{1}$ Universidad de Zaragoza, Facultad de derecho. Correo electrónico: ali.uniza@ gmail.com
} 


\section{INTRODUCCIÓN}

Por su situación en la frontera de tres mundos distintos, el árabe, el norteafricano y el europeo, y por estar rodeado por el Océano Atlántico y el Mar Mediterráneo, Marruecos se ha convertido en uno de los países referentes en lo que respecta al fenómeno migratorio a nivel mundial.

La emigración marroquí en el extranjero ha estado siempre presente en la historia del país, pero a partir del siglo XIX ha aumentado y se orienta hacia Europa. La apertura comercial de Marruecos durante la segunda mitad del siglo XIX dio lugar a una emigración de élites a Francia y a otros países europeos, principalmente a Inglaterra y Gibraltar (Chigueur, 1997).

Hoy en día Marruecos se enfrenta a una situación compleja en el tema de la migración en todas sus dimensiones: los movimientos migratorios económicos, refugiados y solicitantes de asilo, la migración irregular, el tráfico, la migración interna, migración medioambiental, etc. Por eso la comunidad extranjera en Marruecos es bastante diversa (Charef, 2014).

Por ser país tradicional de emigración, Marruecos se ve hoy confrontado a la inmigración de tránsito, temporal o de larga duración. Debido a una situación de estancamiento, Marruecos se ha convertido en un país de inmigración-residencia por defecto, más que de tránsito para numerosos extranjeros.

Por todas estas razones, Marruecos se convirtió a su vez en una tierra de asilo e instalación duradera de los migrantes. Recibe así una inmigración laboral regular, un número relativamente importante de estudiantes internacionales, migrantes en situación irregular, "en tránsito", a menudo de larga duración y, por último, solicitantes de asilo y refugiados.

Frente a esta situación y en función de todo esto ¿cuál es la política seguida por Marruecos en el ámbito de la migración?, y ¿cuáles son los textos legales adoptados para este asunto, tanto

2 Disponible en www.yabiladi.com/.../maroc-pays-demigration-mon.

${ }^{3}$ En 2013, la población migrante marroquí era más de 4,5 millones de personas, según las estimaciones del MRE, una constitucionales 0 legales como acuerdos internacionales? Es lo que vamos a analizar en este texto.

\section{MARRUECOS DE UN PAÍS DE EMIGRANTES A TIERRA DE INMIGRACIÓN Y TRÁNSITO}

Marruecos es el noveno país de emigración en el mundo después de Reino Unido, Alemania e Italia ${ }^{2}$. De acuerdo con el Informe sobre el proyecto de Ley de Presupuesto de 2016, el Ministerio de Marroquíes Residentes en el Extranjero (en adelante 'MRE') estimó que el número de marroquíes residentes en el extranjero ascendía 4,5 millones de personas en el año $2013^{3}$, aproximadamente el $15 \%$ de la población marroquí ${ }^{4}$, frente a los 1,7 millones en 1998.

Tres de cada cuatro inmigrantes marroquíes en el mundo viven en Europa, según el estudio 'Marroquíes del exterior 2013' (Berian, 2013) llevado a cabo por la Fundación Hasan II para los Marroquíes Residentes en el Extranjero. Dicha fundación, que depende del Estado, indica que la comunidad marroquí en el extranjero se estableció en 100 países de los cinco continentes, la mayoría en Europa, con total de un $85 \%$, con Francia a la cabeza, seguida por España, Italia, Bélgica, Países Bajos y Alemania. Su presencia también se estima en un $8,9 \%$ en los países árabes y $0,12 \%$ en Asia y Oceanía. En África, donde se concentra principalmente en Costa de Marfil (1.971) en Senegal (1.900), Mauritania (1.653), Gabón (785) y África Sur (832). Esa distribución se concreta en el siguiente cuadro:

Marroquíes residentes en el extranjero por países entre 2002-2015

\begin{tabular}{|l|l|l|l|}
\hline Países & 2002* & 2012 & 2015 \\
\hline Europa & 2.185 .894 & 3.058 .429 & 4.500 .000 \\
\hline
\end{tabular}

cifra mucho más alta en esta ocasión, porque incluye a los migrantes ilegales.

${ }^{4}$ http://www.bladi.net/marocains-monde-france,42065.html. 


\begin{tabular}{|c|c|c|c|}
\hline Francia & 1.024 .766 & $\begin{array}{l}1.146 .68 \\
2\end{array}$ & $1.500 .000^{5}$ \\
\hline España & 222.948 & 671.669 & $758.000^{6}$ \\
\hline Italia & 287.000 & 486.538 & $437.000^{7}$ \\
\hline Bélgica & 214.859 & 297.919 & $550.000^{8}$ \\
\hline Holanda & 276.655 & 264.909 & $460.000^{9}$ \\
\hline Alemania & 99.000 & 126.954 & $200.000^{10}$ \\
\hline $\begin{array}{l}\text { Gran } \\
\text { Bretaña }\end{array}$ & 30.000 & 26.191 & 70.000 \\
\hline Otros & 29,245 & 38.567 & - \\
\hline $\begin{array}{l}\text { Países } \\
\text { árabes }\end{array}$ & 231.962 & 214.451 & - \\
\hline Libia & 120.000 & 69.276 & $60.000^{11}$ \\
\hline Argelia & 63.000 & 45.451 & $63.000^{12}$ \\
\hline Túnez & 16.000 & 30.635 & $9.5000^{13}$ \\
\hline $\begin{array}{l}\text { Saudí } \\
\text { Arabia }\end{array}$ & 11.973 & 35.724 & $60.000^{14}$ \\
\hline Emiratos & 8.359 & 15.935 & $100.000^{15}$ \\
\hline Otros & 13.345 & 17.430 & - \\
\hline $\begin{array}{l}\text { Fuera de } \\
\text { Europa }\end{array}$ & 160.355 & 796.150 & 1.050 .000 \\
\hline $\begin{array}{l}\text { Estados } \\
\text { Unidos }\end{array}$ & 85.000 & 33.047 & 150.000 \\
\hline Israel & ----- & 700.000 & $800.000^{16}$ \\
\hline Canadá & 70.000 & 53.707 & 100.000 \\
\hline $\begin{array}{l}\text { Países } \\
\text { africanos }\end{array}$ & 5.355 & 9.396 & - \\
\hline
\end{tabular}

\section{* Khadija (2004) \\ ** Fundación Hassan II (2013). **** Según diferentes fuentes.}

Podemos ver en este cuadro que entre los países europeos con más números de emigrantes marroquíes se sitúa Francia 17 en primer lugar, seguido por España, Italia, Países Bajos y Bélgica. También la comunidad extranjera marroquí se encuentra en muchos países árabes, sobre todo en los Estados del Magreb y los países del Golfo ${ }^{18}$. Hoy en día la diáspora marroquí en el extranjero se percibe como un nuevo actor del desarrollo y se posiciona como un alto capital humano y financiero. Representa una fuente esencial de capital extranjero y contribuye al desarrollo del país mediante el envío de remesas, el desarrollo empresarial, la creación de empleo y la generación de ingresos. Además, proporciona nuevos conocimientos y una gran experiencia, que desempeña un papel importante en el desarrollo de capacidades y el progreso de la región y aporta un valor añadido a la diversidad y la riqueza de la experiencia.

Todos los economistas están de acuerdo en la importancia del papel de la migración en el desarrollo de la economía marroquí y la

14 http://www.yabiladi.com/articles/details/16555/chomagearabie-saoudite-irreguliers-sous.html.

$15 \mathrm{http} / / / \mathrm{www}$. lematin.ma/exclusif/marocains-residants-auxemirats_soiree-artistique-en-1-honneur-de-la-communautemarocaine/191749.html.

${ }^{16}$ http://fr.timesofisrael.com/israel-compte-800-000residents-marocains/.

${ }^{17}$ Según el Comité de Asuntos Exteriores de la Asamblea Nacional de Francia, dentro esta cifra de los emigrantes marroquíes en Francia hay más 670.00 de ellos con doble nacionalidad.

${ }^{18}$ Esta migración ha conocido un crecimiento continuo y representa una creciente proporción de la migración marroquí en el mundo árabe. Se trata de una migración temporal para empleos de duración limitada, vinculada a un contrato de trabajo que puede ser renovado o no según las necesidades del Kafile especie de padrino capataz, él es el garante del migrante marroquí ante las autoridades del país. La mayoría de estos migrantes se insertan en una situación de aislamiento social, alta explotación y total dependencia de su Kafile, una parte de migrantes mujeres terminan en la prostitución.

13 http://www.aujourdhui.ma/maroc/societe/recensement-5565-marocains-resident-en-tunisie-117823\#.VdknnPntmko. 
importancia de las transferencias de los inmigrantes para la economía del país.

Según estadísticas de la Oficina de Cambios de Marruecos, las transferencias de los marroquíes residentes en el extranjero para 2015 aumentaron un 3\% superando los 60 mil millones de dírhams.

En la época del Rey de Mohammed VI la política marroquí ha mejorado la situación de los emigrantes de diferentes maneras, y se dota de nuevos componentes como la protección jurídica de los marroquíes residentes en el extranjero, la promoción de la inversión y la mejora de los servicios de acogida, manteniendo el objetivo de preservar los lazos con el país.

El discurso del Rey Mohammed VI el 6 de noviembre de 2005 anunciaba cuatro medidas sobre actividades políticas para conseguir una representación que garantice los derechos cívicos y políticos (Aboussi, 2011): la representación de los nacionales residentes en el extranjero en la "Cámara de Representantes"; la creación de circunscripciones legislativas electorales en el extranjero; la concesión del derecho de voto a las nuevas generaciones, con la revisión correspondiente de la legislación electoral y la creación del Consejo Superior de la Comunidad marroquí en el extranjero. El discurso presentaba estas decisiones como una respuesta a las aspiraciones legítimas de diferentes generaciones de la comunidad marroquí en el exterior, que deseen ejercer su ciudadanía plena con el fin de implicar a los ciudadanos emigrados en todas las instituciones y asuntos públicos (Aboussi, 2011).

Las dos primeras medidas correspondientes a la representatividad de los residentes en el exterior se iban a aplicar en las elecciones legislativas de septiembre de 2007, al final, las autoridades anularon esta intención por motivos técnicos y logísticos, relativos a la dificultad de organizar elecciones en los diferentes países de residencia de los emigrantes marroquíes (Belguendouz, 2009). Ya que era necesario estar en Marruecos el día de elecciones y no existe el voto por correo.

\footnotetext{
${ }^{19}$ En la legislación marroquí, un Dahir es un Decreto real.

${ }^{20}$ Censo General de Población y el Hábitat 2014, en la Web Oficial del Plan En 2014 el ACNUDH.
}

Eso ha hecho que incluso hoy en día la comunidad marroquí en el extranjero esté a la espera de poder participar de manera eficaz en la selección de sus representantes en el futuro próximo. Sabiendo que el derecho de votar y presentarse está garantizado por la Constitución de 2011 en su artículo 17.

La cuarta medida anunciada en 2005 preveía constituir el Consejo de la Comunidad Marroquí en el Extranjero (en adelante 'CCME'). El Consejo era nombrado por S.M. el Rey Mohamed VI en virtud del Dahir ${ }^{19} \mathrm{n}^{\circ} 1.07 .08$, de 21 de diciembre de 2007. Es una institución de carácter consultivo con autonomía administrativa y financiera que se encarga de dar opiniones sobre los asuntos de la emigración y, en particular, las cuestiones que afectan a los marroquíes residentes en el extranjero.

Por otro lado y para poder observar la situación de los extranjeros en Marruecos, en primer lugar, es necesario contar con información precisa sobre la materia resultando imprescindible disponer de datos estadísticos que nos permitan cuantificar cuántos extranjeros hay en el país, debiendo señalar a este respecto que no hay cifras precisas especialmente en lo que se refiere a los inmigrantes ilegales.

Marruecos es el cuarto país árabe más poblado, después de Egipto, Sudán y Argelia. Según los datos de 2014 la población de Marruecos ascendía a 33.848.242 millones de personas, de los cuales cerca de 80.000 eran extranjeros residentes en su territorio (Haut-Commissariat au Plan du Maroc HCPM, 2015).

Marruecos está experimentando la presencia en su territorio de un creciente número de ciudadanos extranjeros, en particular subsaharianos desde principios de 2000. De acuerdo con el HCP, Marruecos tenía en 2014 cerca de 80.000 extranjeros en su territorio 20 .

Según Lahlou, experto del Instituto Nacional de Estadísticas y especialista en migración económica, citado por Chaudier (2013), Marruecos tiene entre 10.000 y 20.000 inmigrantes africanos

http://www.hcp.ma/Note-sur-lespremiers-resultats-duRecensement-General-de-la-Population-et-de-l-Habitat2014_a1516.html-. 
ilegales. Se estima entre 1.000 y 2.000 el número de personas que llegan ilegalmente en Marruecos cada año a Europa, además de 80.000 extranjeros que residen legalmente en 2010, según el Ministerio del Interior. Por otro lado no olvidemos los europeos residentes en situación irregular, 12.000 a 15.000 españoles y otros tantos franceses según lo apuntado por Lahlou, para un total de 40 a 50.000 personas de origen europeo en situación irregular en el país. El resultado es que cerca de 145.000 extranjeros viven en Marruecos, en todas las situaciones administrativas.

Europa es la región líder de origen de los inmigrantes residentes en Marruecos (50\%). Entre los países europeos, Francia es el primer país de inmigrantes, con un $35,1 \%$. El África subsahariana globalmente considerada está en segundo lugar con el $27,7 \%$ de los inmigrantes distribuidos por nacionalidad de manera principal tal como sigue: congoleños $(8,1 \%)$, senegaleses $(4,7 \%)$, malienses $(3,4 \%)$ y nigerianos $(3,4 \%)$. Por último, los países árabes son la tercera región de origen de los inmigrantes que contribuyen con el $22,3 \%$ de su volumen total de los cuales el $13,5 \%$ son de Siria Haut-Commissariat au Plan du Maroc -HCPM, 2009).

Considerado durante décadas un país de emigración y tránsito, Marruecos se ha convertido últimamente en una tierra de asilo y destino para los inmigrantes, sobre todo, del África subsahariana. Frente a esta realidad Marruecos se convirtió en el primer país afectado por el problema de la emigración clandestina compuesta de inmigrantes marroquíes y extranjeros con el objetivo común de llegar a Europa.

Esta evolución se enmarca en un contexto de cambios nacionales, regionales y globales, a nivel demográfico, migratorio y geopolítico, que han obligado a las autoridades marroquíes a aprobar políticas en materia de migración y derecho de asilo.

Para luchar contra esto, en 2003 Marruecos adoptó una legislación (Ley 02-03) Esta Ley regula los diversos aspectos de la migración en Marruecos: la inmigración (entrada y estancia en el país) y la emigración (modalidades de salida del país). Así como las sanciones, administrativas y penales (expulsión, retención, multas y prisión) contra los delitos relacionados con la entrada y estancia no autorizado.

\section{LA DIMENSIÓN LEGISLATIVA}

\subsection{La legislación marroquí sobre migración hasta noviembre de 2003}

Antes de la aprobación de la Ley $\mathrm{n}^{\circ} 02-03$, de 11 de noviembre de 2003, la legislación marroquí sobre migración contenía varios textos dispersos, que en su mayoría datan de la época del Protectorado durante los años treinta y cuarenta, y que regulaban tanto la entrada como la estancia y residencia en el país y la salida de este (Khrouz, Ouardi y Rachidi, 2009). El arsenal jurídico heredado del Protectorado incluye los textos siguientes:

La Orden de 8 de enero de 1915 (modificada el 30 de junio de 1926), conforme a la que la entrada en el territorio de la zona francesa del Imperio Jerifiano, por mar o aire está condicionada para los extranjeros a la presentación de un pasaporte válido. En este pasaporte tiene que figurar, además, un visado de entrada marroquí, excepto si el titular pertenece a un país con el cual Marruecos ha firmado un acuerdo dispensando del visado con aplicación del principio de reciprocidad.

- El Dahir de 15 de noviembre de 1934 por el que se regula la inmigración en Zona Francesa del Imperio Jerifiano. Este texto organiza un régimen de entrada al territorio en consideración de las necesidades económicas a toda persona de nacionalidad extranjera que migra a Marruecos para ejercer allí una actividad profesional, sea de la naturaleza que sea, remunerada o no, por su propia cuenta o por cuenta ajena.

- El Dahir de 13 de julio de 1938 por el que se regula la emigración de los trabajadores marroquíes, complementado y modificado por el Dahir de 25 de marzo de 1939. 
- El Dahir de 21 de febrero de 1951 por el que se modifica y se complementa el Dahir de 15 de noviembre de 1934.

- El Dahir de 17 de abril de 1959, del Ministerio de Trabajo y Seguridad Social haciendo extensible a la antigua zona del Protectorado español y la provincia de Tánger la legislación sobre la inmigración en vigor en la zona sur.

Esta legislación y reglamentación completamente superadas, hablaba aún de zona francesa del Imperio Jerifiano y de zona española, y hacía todavía referencia a ciertas instituciones o servicios del Protectorado francés como el Secretario General del Protectorado, el Tesorero General del Protectorado, el Director de Interior, el Comisario Residente General.

Hasta el mes de mayo de 2003, el Dahir vigente aplicable a las infracciones en materia de emigración clandestina se remontaba al 6 de noviembre de 1949. El anacronismo de este Dahir queda patente en las referencias a instituciones coloniales como el Protectorado, la zona francesa de Marruecos, la zona española y a las sanciones formuladas en la moneda de aquella época (el franco), como se desprende de la lectura del artículo 10 del Dahir:

"Estará sujeto a una pena de prisión de un mes a dos años y a una multa de 12.000 a 240.000 francos, o sólo a una de estas dos penas, todo trabajador marroquí que salga del territorio de la zona francesa sin los documentos contemplados en los artículos 4, 6 y 7 o que, con vistas a obtener la expedición de dichos documentos, haya realizado declaraciones falsas sobre su identidad o haya utilizado documentos expedidos a otro marroquí.

[...] En caso de reincidencia en el mismo año, la multa se duplicará y deberá obligatoriamente sumarse a una pena de prisión. Estarán sujetas a las mismas penas, las personas que, conscientemente, haya ayudado o incitado a uno o varios individuos a cometer

\footnotetext{
${ }^{21}$ El artículo 3 del Decreto Real de 8 de noviembre 1949, declaraba que: "Los trabajadores marroquíes no pueden abandonar el territorio de la zona francesa de nuestro imperio, si no se les proporciona: Un contrato de trabajo; un
}

infracciones a lo dispuesto en el presente Dahir o a órdenes aprobadas para la ejecución del mismo [...]".

Este Dahir, conocido por los abogados marroquíes como el Dahir de "las pulgas y los chinches", incluye en su artículo cuatro ${ }^{21}$ una disposición humillante que obliga a los trabajadores marroquíes que quieren emigrar a disponer de un "certificado de desinsectación" antes de salir del territorio de la zona francesa.

Las únicas modificaciones aportadas por las autoridades marroquíes desde 1956 han consistido en la adaptación de los textos adoptados durante el período del protectorado a los diferentes cambios acaecidos en la estructura administrativa del país desde su independencia. De este modo, el conjunto de dichos textos se refiere a la zona internacional de Tánger y a la ex zona de Protectorado español (Norte de Marruecos) en virtud del Decreto del 16 de noviembre de 1962 del Ministro del Interior (Barros, Lahlou, Escoffier, Pumares y Ruspini, 2002). Lo mismo ha sucedido en 1969 referente a la zona de Ifni (igualmente bajo Protectorado español) y después para el ex Sáhara español, cedido por España a Marruecos en 1975.

Exceptuando esta refundición territorial y cinco convenciones de establecimiento que han tenido lugar entre 1962 y 1979 con cinco países africanos (Libia, Argelia, Senegal, Túnez y Mauritania), el Derecho marroquí ha permanecido inalterable, exceptuando el hecho de que desde 1956 es aplicado por un Estado independiente, en una situación nacional y regional y en un marco económico, político y social completamente distintos de las condiciones que regían en el origen de su redacción.

Tras casi medio siglo de independencia y con los cambios que ha experimentado el fenómeno migratorio, este arsenal jurídico heredado de la época del Protectorado ha quedado obsoleto. La actualización de las leyes vigentes en esta materia

pasaporte; una certificado de antecedentes penales un certificado médico acompañado de un certificado de desinsectación". 
se ha convertido en una necesidad. Así, un proyecto de ley, preparado hace años, fue finalmente aprobado por el Consejo del Gobierno el jueves 16 de enero de 2003 y sometido al Parlamento.

\subsection{La Ley $n^{\circ} 02-03$ sobre entrada y estancia de extranjeros en el Reino de Marruecos, emigración e inmigración irregulares}

A nivel interno, en lo que respecta al desarrollo normativo del régimen migratorio en Marruecos, el Gobierno marroquí aprobó en el año 2003 La ley $n^{\circ}$ 02-03 de 11 de noviembre sobre Entrada y estancia de extranjeros en Marruecos, emigración e inmigración irregulares. Esta Ley puso fin a un vacío jurídico en la materia, Marruecos se dotó de un marco jurídico moderno, conforme a sus compromisos internacionales, y dio respuesta a una nueva situación, en la que, como ya se ha analizado anteriormente, el país se convierte en un lugar de tránsito y destino cada vez más privilegiado de inmigrantes procedentes de otros países del Magreb, subsaharianos e incluso europeos (Khachani, 2006).

Esta Ley regula los diversos aspectos de la migración en Marruecos: la inmigración (entrada y estancia en el país) y la emigración (modalidades de salida del país). Así como las sanciones, administrativas y penales (expulsión, retención, multas y prisión) contra los delitos relacionados con la entrada y estancia no autorizado. El Decreto de aplicación de esta Ley fue aprobado el 1 de abril de 2010 (Décret n 2-09-607 du 15 rabii II 1431 (1er avril 2010) pris pour l'application de la loi $n^{\circ}$ 02-03 relative à l'entrée et au séjour des étrangers au Royaume du Maroc, à l'émigration et l'immigration irrégulières) ${ }^{22}$.

\footnotetext{
${ }^{22}$ Décret $\mathrm{n}^{\circ}$ 2-09-607 du 15 rabii II 1431 (1er avril 2010) pris pour l'application de la loi $\mathrm{n}^{\circ}$ 02-03 relative à l'entrée et au séjour des étrangers au Royaume du Maroc, à l'émigration et l'immigration irrégulières, Bulletin officiel n 5836 du 6 mai 2010

http://adala.justice.gov.ma/production/html/Fr/liens/..\%5C16 4711.htm-.

${ }^{23}$ La Ley n ${ }^{\text {o }}$ 03-03 o ley antiterrorista, llegó tras los atentados del 11-S. Esta iniciativa por el Gobierno marroquí fue
}

Por otro lado, la Ley $\mathrm{n}^{\circ} 02-03$ constituye una base legal para reforzar el control de las fronteras del país. Debemos destacar el hecho de que esta disposición fue adoptada apenas seis meses después de la Ley $n^{\circ} 03-03^{23}$ relativa al terrorismo. La norma marroquí presenta un texto casi copiado del Derecho migratorio francés, adoptado sobre la base de las preocupaciones y circunstancias relacionadas con la migración en Francia y que no son las mismas en nuestro caso. Marruecos adoptó esta ley con el objeto de regular varios aspectos relacionados con la migración:

- La unificación y la actualización de los textos legislativos y reglamentarios que regulan esta materia.

- La codificación de los delitos, las infracciones y las sanciones asociadas a los intentos de emigración clandestina y al tráfico ilegal de personas mediante una calificación penal precisa.

- La racionalización de las modalidades y los criterios de estancia en el Reino.

- La armonización de las penas contempladas con las disposiciones del Código Penal.

- Cumplir los convenios internacionales relativos a las obligaciones y a los derechos de los inmigrantes y de los extranjeros establecidos, y asumir plenamente los compromisos con los principales socios, en particular en materia de lucha común contra la inmigración clandestina transfronteriza, en su doble componente nacional y extranjera.

Un elemento positivo de esta Ley sería su contribución al proceso de armonización de la legislación marroquí sobre la inmigración y la alineación progresiva de las políticas marroquíes con el principio de los derechos humanos, sin olvidar en este contexto las limitaciones

promovida por el sector más duro del Ministerio del Interior y la Dirección de Seguridad Territorial (en adelante 'DST'). $\mathrm{Su}$ proceso de tramitación parlamentaria ha sido uno de los más complejos de los últimos años por la oposición que el proyecto suscitó en amplios sectores del espectro político marroquí. Pero los atentados de Casablanca terminaron con los largos debates parlamentarios y la Ley fue aprobada apenas una semana después de los atentados 16 de mayo de 2003. 
inherentes a ella. Al menos dieciséis artículos de esta ley repiten fielmente los textos europeos, especialmente franceses, sobre todo en materia de migración.

En general, hay dos tipos de normas legales en materia de migración: uno es el que organiza el desplazamiento de poblaciones y sanciona cualquier violación de los reglamentos de la zona, y otro es el que protege a los migrantes. La primera categoría incluye normas relativas a la entrada y residencia de los extranjeros en general (incluidos los migrantes) en el país y la emigración desde el interior del país. Esta categoría de normas es utilizada por los Estados con referencia a ciertos principios generales en los que la mayoría están de acuerdo, tales como la no discriminación y la reunificación familiar. La segunda categoría de normas se refiere a todas las reglas que tienen como objetivo proteger a los migrantes. Estas reglas son en gran medida internacionales, estando incluidas en las convenciones universales y regionales, cuyas disposiciones deben ser incorporados en la legislación nacional.

El texto de la Ley $\mathrm{n}^{\circ}$ 02-03 comprende tres títulos. El primero, consagrado a la entrada y estancia de los extranjeros en el Reino de Marruecos, se compone de 49 artículos reagrupados en 7 capítulos: disposiciones generales, permisos de estancia, traslado a la frontera, de la expulsión, disposiciones comunes para el traslado a la frontera y la expulsión, disposiciones varias, Circulación de los extranjeros y disposiciones penales. El segundo título es mucho más corto, integrado por siete artículos (50 a 56) consagrados enteramente a las disposiciones penales relativas a la emigración e inmigración irregulares. El tercer título con dos artículos (art 57y 58) se refiere a las disposiciones transitorias.

El artículo primero de dicha ley dispone que: "Bajo reserva de la aplicación de los convenios internacionales debidamente publicados, la entrada y la estancia de extranjeros en el Reino de Marruecos se regirán por las disposiciones de la presente ley", lo que constituye un reconocimiento del lugar que ocupan estas convenciones internacionales en el dispositivo legislativo marroquí en materia de entrada y estancia de extranjeros.

Esta ley define las condiciones de acceso al país, regula los procedimientos de obtención de un permiso de estancia y los casos en los que dichos permisos pueden revisarse, situación que se produce cuando las autoridades disponen de información o tienen conocimiento de hechos que permiten considerar que las condiciones de estancia de un extranjero no se cumplen, en particular en caso de que dichas estancia pueda suponer una amenaza para la seguridad nacional e internacional.

En general, los artículos 3 y 4 de la Ley $n^{\circ} 02-03$ someten a los extranjeros que cruzan las fronteras de Marruecos a la supervisión de las autoridades. El artículo 3 se refiere al control de validez del pasaporte y el visado, y dispone que:

"[...] todo extranjero que llegue al territorio nacional estará obligado a presentarse a las autoridades competentes encargadas del control en los puestos fronterizos, con un pasaporte de su Estado o con cualquier otro documento en vigor reconocido por el Estado marroquí como documento de viaje en vigor $y$, en su caso, con el visado exigible, expedido por la administración".

Por su parte el artículo 4 prevé un control cuya necesidad y, en cierta medida, el contenido se deja a la discreción de las autoridades, señalando lo siguiente:

"[...] el control efectuado en el momento de la verificación de uno de los documentos mencionados en el artículo 3 podrá también referirse a los medios de subsistencia y los motivos del desplazamiento a Marruecos de la persona interesada y a las garantías de su repatriación, teniendo en cuenta en particular las leyes y los reglamentos relativos a la inmigración".

Asimismo, esta Ley otorga a la Administración la facultad de proceder a la retirada del permiso de estancia o de decidir, de manera razonada, la expulsión de un residente extranjero y su traslado a la frontera. La Administración también puede dictar la decisión de prohibición de entrada en el 
territorio, contra la que la persona afectada puede interponer un recurso ante las instancias judiciales conforme al artículo 4 anteriormente citado.

En general al extranjero que cumple las condiciones de entrada se le permite permanecer en el territorio de Marruecos durante el período de validez de su visado. En caso de estancias superiores a tres meses, el extranjero antes de la expiración de su visado o antes de noventa días o de la extinción de la vigencia de su visado, debe acudir a la jefatura de policía que corresponde a su ciudad para realizar los trámites para la solicitud de un permiso de residencia. Por lo tanto, la tarjeta de registro es el título principal que todos los extranjeros deben obtener.

La nueva Ley especifica que hay dos permisos de residencia en Marruecos: la tarjeta de inscripción y la tarjeta de residencia (artículo 5). El primer título es expedido para los residentes extranjeros en Marruecos por un periodo superior a tres meses. Por su parte la tarjeta de residencia se debe obtener por los extranjeros cuyo periodo de residencia ininterrumpida en Marruecos supere los cuatro años. Los artículos 9 a 18 de la Ley 02-03 establecen las condiciones para la obtención de estas tarjetas y proporcionan información sobre los tipos de tarjetas de inscripción y residencia y sobre quién las puede tener (Khadija, 2004).

La Ley introduce tres tipos de tarjetas de inscripción: para los visitantes, estudiantes y trabajadores migrantes, con especial referencia a la actividad. Dicha tarjeta debe ser obtenida dentro de las 48 horas de la entrada y puede tener una duración de un año prorrogable hasta 10 años.

Ambos títulos, la tarjeta de inscripción y la de residencia, pueden ser denegados a los extranjeros que no cumplan las condiciones a las que está sujeta la expedición de los permisos de estancia. En este caso el permiso de estancia podrá ser retirado si:

- El extranjero no presenta los documentos y justificantes contemplados por vía reglamentaria.

\footnotetext{
${ }^{24}$ En virtud del artículo 7 del Dahir $N^{\circ} 421-66$ de 20 de octubre de 1969 relativo a las atribuciones de los agentes diplomáticos y los cónsules destinados en el extranjero: "[...] los agentes diplomáticos y los cónsules tienen el deber de
}

- El titular del permiso es objeto de una medida de expulsión o de una decisión judicial de prohibición de entrada en territorio marroquí (Artículo 19 de la Ley 02-03).

El extranjero al que se deniegue o retire el permiso de estancia tiene derecho a interponer un recurso ante el Presidente del Tribunal Administrativo, en su calidad de juez competente para pronunciarse sobre medidas cautelares por vía de urgencia, en un plazo de quince días tras la fecha de notificación de la decisión de la denegación o la retirada. No obstante, el recurso ante la justicia no impide que se adopte la decisión de traslado a la frontera o de expulsión (artículo 20 de la Ley $n^{\circ}$ 02-03). La anulación de esta decisión puede ser solicitada al Presidente del Tribunal administrativo, en un plazo de cuarenta y ocho horas tras su notificación. El Presidente o su delegado deciden en un plazo de cuatro días completos a partir del momento en que recibe la solicitud. El plazo del recurso tiene efecto suspensivo de la ejecución, es decir, que la decisión de traslado a la frontera no se puede ejecutar antes de que venza el período de 48 horas tras su notificación o antes de que el Presidente del Tribunal Administrativo haya decidido sobre el caso (artículos 24 y 28 de la Ley $n^{\circ} 02-03$ ).

Los recursos de anulación de las decisiones de prohibición de entrada, expulsión o traslado a la frontera pueden presentarse incluso cuando haya vencido el plazo de recurso administrativo de cuarenta y ocho horas fijado en el artículo 23, si el interesado reside fuera de Marruecos (artículo 32 de la Ley $n^{\circ} 02-03$ ).

También la Ley 02-03 reconoce a los nacionales marroquíes residentes en el extranjero la posibilidad de recurrir, de conformidad con las disposiciones de las Convenciones de Viena de relaciones diplomáticas y de relaciones consulares, a los consulados e instituciones diplomáticas de Marruecos 24 .

prestar asistencia a los marroquíes de su circunscripción, tanto si son objeto de un procedimiento penal por parte de las autoridades del país de residencia, como si no están en condiciones de subsistir por sus propios medios". Esta 
Algunas categorías de extranjeros pueden conseguir un permiso de residencia en Marruecos a través de un procedimiento más sencillo bien sea sirviéndose de sus propios recursos financieros o económicos como trabajadores, o por sus cónyuges marroquíes. En el otro extremo, una categoría de extranjeros que se enfrentan a mayores dificultades es la de aquellos que desean trabajar en Marruecos, puesto que para validar su estancia en virtud de un trabajo encontrado el empleador debe obtener la certificación conocida por la ANAPEC (Agence nationale de promotion de I'emploi et des compétences), demostrando que el perfil deseado no se encuentra entre los solicitantes de empleo nacionales (Khrouz, 2013). Por otra parte, para el matrimonio de un extranjero con un marroquí, también minuciosamente regulado, es necesario conseguir la autorización del juez, debiendo además asegurarse la situación financiera y administrativa regular del futuro cónyuge. En este caso, la conversión al Islam es obligatoria, cuando el cónyuge, en este caso la mujer, es musulmana.

Sin embargo, en la práctica, la mayoría de los estudiantes extranjeros proceden a renovar su título de uno a tres meses después de su caducidad, evitaron muchos trámites. Bajo ciertas condiciones, el extranjero puede ver como se le deniega el permiso de residencia y se ve obligado a abandonar el territorio marroquí o pasa a encontrarse en situación irregular.

Los miembros de las misiones diplomáticas acreditadas en el país ahora se incluyen en sistema especial de entrada establecido en el artículo 2 de la Ley 02-03, que establece que, en condiciones de reciprocidad, sus disposiciones no se aplican: "[...] a los agentes de las misiones diplomáticas y consulares y sus miembros acreditados en Marruecos, con estatuto diplomático".

La legislación marroquí actual contempla varias sanciones por delitos relacionados con la migración. Estas sanciones están contenidas inicialmente en el Código Penal, cuyos artículos

disposición también es válida para los extranjeros presentes en Marruecos de acuerdo con los artículos 4, 24 y 36 de la
317 y 325 castigan el incumplimiento de las medidas de residencia forzosa y medidas de seguridad.

La gran parte de esta nueva legislación migratoria se dedica a la represión de la migración ilegal (inmigración y emigración) (Khadija, 2004). Según el artículo 42, la entrada o intento de entrada sin documentos válidos y la estancia por un período más largo que el permitido respectivamente serán sancionados con una multa de 2.000 a 20.000 Dirhams (200 a $2.000 €$ ) y/o prisión entre uno y seis meses.

La Ley $n^{\circ}$ 02-03 reprime con dureza la infracción del tráfico de personas, previendo tres tipos de sanciones: penales, judiciales y administrativas. Se prevén multas y penas de prisión de 10 a 15 años para quienes organicen o faciliten este tráfico; en este caso se refiere a funcionarios, miembros de las fuerzas de seguridad y empleados de empresas de transporte; y multas de 50.000 a 500.000 Dirhams $(5.000$ a $50.000 €)$ en caso de participación o asistencia a acciones de emigración irregular o inmigración. La pena puede llegar a los 15 a 20 años si se causa una incapacidad de la persona víctima de ese tráfico, y puede llegar hasta la cadena perpetua si dicho tráfico provoca la muerte de las personas transportadas (artículo 51) (Khachani, 2006).

Por su parte, los menores de edad y mujeres embarazadas acompañadas de sus hijos menores de edad no son considerados por la legislación marroquí como migrantes ilegales y no son castigados por su situación irregular. Así, el artículo 26 de la Ley $\mathrm{n}^{\circ}$ 02-03 prohíbe, en sus apartados 7 y 8 , la expulsión del territorio marroquí de las: "[...] mujeres extranjeras embarazadas y los menores extranjeros".

\subsection{Críticas a la Ley $02-03$. Los límites de la legislación migratoria marroquí.}

Esta Ley ha recibido fuertes críticas, tanto desde las organizaciones de la sociedad civil nacionales como por parte de las organizaciones

Ley $\mathrm{N}^{\circ}$ 02-03 de entrada y estancia de extranjeros en el Reino Marruecos y de emigración e inmigración irregulares. 
internacionales de derechos humanos, por su carácter represivo hacia la inmigración "irregular" y las lagunas en la protección de las personas migrantes.

Entre los informes más críticos a nivel nacional se encuentra el documento conjunto publicado en julio de 2013, por el CNDH, la DIDH y la Oficina de Rabat de la OIM, que sugieren varias recomendaciones al Gobierno de Marruecos.

El Informe del Comité de Protección de los Derechos de Todos los Trabajadores Migratorios y de sus Familiares de Naciones Unidas (2013) incluye un conjunto de observaciones finales sobre la nueva política migratoria marroquí.

En este sentido, observamos que esta nueva disposición parece responder, al menos en parte, a presiones exteriores cuyos fundamentos corresponden al ámbito de la seguridad, y se inscribe en una coyuntura internacional y regional que da prioridad a la dimensión de la seguridad en detrimento de la de los derechos humanos. La opción por la seguridad de este texto legal aparece en diferentes artículos, argumentado las medidas adoptadas por la amenaza a la seguridad y el orden público 25 . Esta idea se expresa de forma recurrente en los artículos 4, 16, 17, 21, 25, 27, 35,40 y 42 . El texto no hace referencia en ningún momento a los derechos políticos, económicos y sociales de los extranjeros: libertad de expresión y de opinión, de adscripción sindical, derecho a la salud, derechos establecidos en la Convención Internacional sobre la Protección de los Derechos de todos los Trabajadores Migrantes y sus Familias.

Esta Ley supone una contradicción con dicha Convención, recogida en la Resolución 45/15 de la Asamblea General de las Naciones Unidas, de la que Marruecos fue uno de los primeros países firmantes, el 14 de junio de 1993, y que sigue siendo, en Derecho internacional, una de las principales referencias en esta materia.

La Convención garantiza a todos los trabajadores migrantes, con o sin papeles, derechos destinados

\footnotetext{
${ }^{25}$ Nos encontramos con el concepto de "orden público" en muchos artículos de la Ley 0203 . Esta idea parece haber reemplazado la famosa frase Koloma min chaänihi, cuyo
}

a protegerlos frente a cualquier forma de abuso y, en particular, el derecho a la vida, a la libertad y a la seguridad de la persona, el derecho a la igualdad con los autóctonos y el derecho a la propiedad, la protección frente a la violencia, la libertad de salir del país, medidas de protección en el momento de la expulsión, el respeto de los derechos en caso de arresto y de persecución penal, así como el derecho a la reparación en caso de arresto y detención ilegales (Khachani, 2006).

En efecto, la nueva legislación marroquí de extranjería ha transformado la emigración en una infracción y prevé numerosas disposiciones represivas, asimismo otorga más poderes a las fuerzas de seguridad y alimenta la discriminación, supone una base legislativa y legal para reforzar el control de las fronteras del país (Comisión española de ayuda al refugiado, 2013).

Cabe resaltar que esta Ley hace escasa mención a las modalidades de emigración regular, no recoge derechos para los inmigrantes marroquíes en situación irregular en países foráneos, y pone en marcha pocos dispositivos para proteger a los migrantes de abusos y de injusticias administrativas en el territorio nacional (Khadija, 2004).

Según Perrin (2008) la Ley de 2003 no considera la estancia de los migrantes como indicativa de una voluntad de permanencia y de instalación en el territorio nacional sino como manifestación de un tránsito con miras a entrar en Europa.

De la misma manera, la nueva Ley de extranjería marroquí reglamenta por primera vez la expulsión de los extranjeros. La expulsión puede ser determinada por la Administración cuando se estima que la presencia de un extranjero en el territorio marroquí constituye una amenaza grave para el orden público. Sin embargo, la noción de orden público no es precisa, lo que deja un amplio margen de interpretación y puede vulnerar los derechos de los migrantes. El extranjero objeto de una decisión de expulsión o de reconducción a la frontera es, según la norma, enviado al país del

significado literal es "todo lo que es susceptible", utilizado a menudo en este texto, lo que deja la puerta abierta a una interpretación amplia por parte de la Administración. 
que tiene la nacionalidad, al país donde se le otorgó documentación válida para viajar, o bien a un país donde es legalmente admisible.

Por otra parte Marruecos no considera a los migrantes subsaharianos como trabajadores y no les aplica la Convención apuntada, a pesar de que muchos especialistas consideren que la misma también se aplica a los migrantes que salen de su país para encontrar trabajo.

Marruecos dejó de pertenecer a la Organización de la Unidad Africana desde 1984 por el problema de Sáhara, pero en teoría sigue estando ligado a la Convención de la OUA, que rige los aspectos propios a los problemas de los refugiados en África porque nunca la ha denunciado oficialmente. Cuando se confirmó con su solicitud de reingreso en la Organización 32 años después de la fecha de su retirada, en el $27^{\mathrm{a}}$ cumbre de la Unión Africana celebrada el 16 de julio de 2016 en la capital ruandesa Kigali, a la que Marruecos acudió con una nutrida representación encabezada por el monarca. Sin embargo, la Organización debería hacer mayores esfuerzos para garantizar la aplicación en la práctica de esta Convención.

Por lo que se refiere a la jurisprudencia, la aplicación de la legislación sobre los extranjeros por los tribunales administrativos está limitada en la mayoría de decisiones a la inmigración "irregular". Así la jurisprudencia del Tribunal Supremo disponible en materia de derechos de los extranjeros se limita generalmente a las apelaciones contra las decisiones de denegación de la expedición de la tarjeta de residencia. La complejidad de los procedimientos judiciales y el obstáculo de la lengua oficial utilizada en los tribunales, complican la situación del extranjero y no le otorga el derecho a defenderse, en ausencia de asistencia judicial.

Y también la complejidad del proceso y los procedimientos para la concesión de asistencia jurídica provoca dificultades para los migrantes para conseguir una defensa real o simplemente para tener acceso a la justicia o para hacer frente a situaciones de emergencia.

A pesar de que la Ley 02-03 garantiza en algunas de sus disposiciones la posibilidad de que el extranjero utilice algún tipo de defensa, pudiendo citar al respecto:

"Artículo 4: [...] Los extranjeros a los que se deniegue la entrada tendrán derecho a advertir de ello, o a hacer que se advierta de ello, a la persona con la que hayan indicado que iban a permanecer, al consulado de su país o al abogado de su elección. [...]

Artículo 23: El extranjero que sea objeto de una decisión de traslado a la frontera podrá, en las cuarenta y ocho horas siguientes a la notificación, solicitar la anulación de dicha decisión al Presidente del Tribunal Administrativo, en su calidad de Juez de Sala.[...] El extranjero podrá solicitar al Presidente del Tribunal Administrativo o al delegado de éste la intervención de un intérprete y la comunicación del expediente que contenga los documentos en base a los cuales se ha adoptado la decisión.[...] El extranjero contará con la asistencia de su abogado, si lo tiene. Podrá solicitar al Presidente o al delegado de éste la designación de un abogado de oficio. [...] A partir de la notificación de la decisión de traslado a la frontera, el extranjero podrá advertir de ello, de inmediato, a un abogado, al consulado de su país o a una persona de su elección. [...] Artículo 34: [...] Se informará inmediatamente al extranjero, por medio de un intérprete, en su caso, de sus derechos. [...]

Artículo 36: Durante el tiempo de permanencia del extranjero, el Fiscal del Reino deberá desplazarse al lugar, verificar las condiciones de la estancia y acceder al registro contemplado en el último apartado del artículo 35 anterior".

En este sentido, evocamos algunos casos presentados a los jueces en algunos tribunales marroquíes en los que no se contó con la presencia de un abogado que asumiese la defensa del extranjero afectado. Son los asuntos, por ejemplo, James Vincent, Omoruyi Kenneth, Sinissia Juan, o Demersseman Malika ante la Primera Instancia de Khemisset, en cuyas sentencias no se hace 
ninguna mención a la presencia de un abogado (Khrouz, Ouardi y Rachidi, 2009).

\subsection{Más instrumentos nacionales relacionados con la Ley de migración en Marruecos}

\subsubsection{El nuevo Código de Trabajo de Marruecos}

En el ámbito del Derecho laboral, el empleo de trabajadores extranjeros está regulado por el capítulo $\mathrm{V}$ del Código de Trabajo, conforme a la Ley $\mathrm{N}^{\circ}$ 65-99 de 11 de septiembre de 2003, que estipula en su artículo 516 que: "[...] todo empleador que desee contratar a un trabajador extranjero deberá obtener una autorización de la autoridad gubernamental encargada de las cuestiones de trabajo. Esta autorización se concederá en forma de visado estampado en el contrato de trabajo".

En virtud de las disposiciones del artículo 521 del Código de Trabajo, y a fin de proteger a los trabajadores extranjeros presentes en Marruecos, se imponen multas de entre 2.000 y 5.000 Dirhams a los empleadores que no obtengan la autorización prevista en el artículo 516, que contraten a trabajadores extranjeros sin dicha autorización, que contraten a trabajadores extranjeros cuyo contrato no se ajuste al modelo previsto en el artículo 517 o que infrinjan las disposiciones previstas en los artículos 518 y 519 . El criterio para la concesión del visado para el contrato de trabajo de los extranjeros responde a un doble objetivo: por una parte, al interés por promover el empleo de la mano de obra marroquí $y$, por otra, dar respuesta a las necesidades del país en lo que se refiere a la competencia de extranjeros necesarias para el desarrollo de la economía nacional y a la garantía de los derechos de estos.

En el plano jurídico, la reglamentación en vigor, en particular el Decreto del Ministro de Empleo y Formación Profesional de 9 de febrero de 2005, exige la presentación de un certificado expedido por el Organismo Nacional de Promoción del Empleo y las Competencias Profesionales (ANAPEC), y su anexo de 25 de noviembre de 2005 dispensa a ciertas categorías de trabajadores extranjeros.

Cabe señalar asimismo que Marruecos está comprometido por convenciones de establecimiento con Argelia, Túnez y Senegal. Los residentes de esos países son tratados como nacionales.

\subsubsection{La Ley de nacionalidad marroquí}

El acceso a la nacionalidad marroquí está organizado por el Dahir $\mathrm{n}^{\circ} 1.58 .250$, de 6 de septiembre de 1958 , modificado por la Ley $\mathrm{n}^{\circ}$ 62.06 promulgada por el Dahir $n^{\circ} 7.1 .80$ de 23 de marzo, 2007. El objetivo principal de esta reforma era establecer la igualdad entre mujeres y hombres dando a la madre marroquí el derecho a transmitir su nacionalidad a sus hijos habidos en un matrimonio mixto. Por lo tanto, el artículo 6 se ha completado de la siguiente manera: "[...] es marroquí, el niño nacido de padre marroquí o de madre marroquí".

La reforma del Código de la nacionalidad incluido en la citada Ley $n^{\circ}$ 62-06, se llevó a cabo en respuesta a las expectativas legítimas de todos los marroquíes y los ciudadanos afectados por este Código, incluyendo los marroquíes residentes en el extranjero.

Con respecto a la naturalización, el artículo 11 estipula que el extranjero que lo haya solicitado no puede ser naturalizado en caso de que no cumpla las siguientes condiciones:

- Tener una residencia permanente y regular durante los cinco años anteriores a la solicitud, y residir en Marruecos hasta que se haya adoptado una decisión sobre esta solicitud.

- Ser mayor de edad en el momento de presentación de la solicitud.

- Observar una buena conducta y moral y no haber sido condenado por delito grave, especialmente por actos que constituyen delito de terrorismo etc.

- Justificar el conocimiento suficiente de la lengua árabe.

- Tener medios económicos suficientes.

- Presentar un certificado médico que demuestre que está en buen estado de salud. 
Esta última condición puede constituir una discriminación respecto a los minusválidos, en función de la interpretación que haga de la misma.

\subsubsection{Disposiciones relativas a los refugiados en} Marruecos

En lo que se refiere al marco normativo que regula la protección de las personas refugiadas, cabe señalar que Marruecos ratificó la Convención de Ginebra de 1951 sobre el Estatuto de los Refugiados el 7 de noviembre de 1956. El año siguiente, se aprobó el Real Decreto 5-57-1256 por el que se establecen disposiciones para la aplicación de la Convención de Ginebra y que encomienda la protección jurídica y administrativa de los refugiados a la Oficina de Refugiados y Apátridas (en adelante 'BRA', según sus siglas en francés). Con arreglo a su organización estructural, esta oficina se encuentra jerárquicamente bajo la dirección del Ministerio de Asuntos Exteriores y de Cooperación de Marruecos. El artículo 2 de este Real Decreto establece que la BRA reconocerá la condición de refugiado a toda persona que se encuentre bajo el mandato del Alto Comisionado de las Naciones Unidas para los Refugiados (en adelante ACNUR) o que cumpla con los criterios de la definición de refugiado conforme a lo estipulado en la Convención de Ginebra. Además, esta norma establece que la BRA deberá entregar los documentos identificativos necesarios para que las personas bajo este mandato puedan desarrollar las actividades comunes y ordinarias de la vida civil 26 . Los derechos y deberes de los refugiados en Marruecos obedecen a las disposiciones de la Convención de Ginebra de 1951, incluyendo los derechos económicos, sociales, culturales, la libertad de circulación y de residencia, en virtud del artículo 29 de la Convención.

Por otro lado, el último párrafo del artículo 30 de la Constitución precisa que: "[...] las condiciones de extradición y concesión del derecho de asilo están definidas por la ley" y que Marruecos dispone

\footnotetext{
${ }^{26}$ Sin embargo, el estatuto de refugiado no da derecho a la obtención de una tarjeta de residencia, lo que impide trabajar en situación regular, acceder a la educación o a la salud pública o circular libremente; con lo cual parece que el
}

de una legislación específica para refugiados y solicitantes de asilo, contenida en el Decreto $n^{\circ} 2$ 57-1256 de 29 de agosto de 1956 por el que se establecen las modalidades de aplicación de la Convención sobre el Estatuto de los Refugiados de 1951.

En la práctica jurídica, en Marruecos se permite a los refugiados elegir entre integrarse jurídicamente en el país de asilo o regresar libremente a su país de origen o incluso solicitar su restablecimiento en otro país de asilo.

Así, es posible para los refugiados que residan durante cinco años en Marruecos solicitar la nacionalidad de acuerdo con el Dahir relativo al Código de nacionalidad. El jefe de la BRA, forma parte de la Comisión Nacional que resuelve las solicitudes de nacionalidad marroquí.

A pesar de los esfuerzos realizados en este tema, la legislación migratoria marroquí sigue siendo objeto de críticas, que hasta la fecha, ni el Real Decreto 5-57-1256 sobre protección de los refugiados, $\mathrm{ni}$ la Ley $\mathrm{n}^{\circ} 02-03$ contemplan aspectos relativos al procedimiento de solicitud $\mathrm{ni}$ a la forma en la que la instrucción de casos de asilo debe realizarse. Estos graves vacíos normativos ponen de manifiesto las carencias del sistema que conducen a que desde la firma y ratificación por parte de Marruecos la Convención de Ginebra se ha mostrado completamente ineficaz en este Estado.

La inexistencia de un procedimiento eficaz ha provocado que, hasta el anuncio de la nueva política migratoria marroquí en 2013, sea el ACNUR quien se ha ocupado de 'registrar' a los solicitantes de asilo, determinar la condición de refugiado de conformidad con su mandato y emitir la documentación necesaria que acredita la condición de beneficiario de protección internacional.

Sin embargo los documentos expedidos por ACNUR no siempre constituyen una protección suficiente frente a las autoridades de Marruecos.

derecho de no expulsión sea el único al que pueden aspirar los solicitantes de asilo y los refugiados reconocidos en Marruecos. 
Por otro lado, la ausencia de un régimen de asilo en el Derecho nacional implica que las personas provistas de un documento identificativo de refugiado emitido por ACNUR tienen dificultades para conseguir un permiso de residencia o ver reconocido su derecho a trabajar27.

Cabe señalar que Marruecos es parte en una serie de acuerdos internacionales que protegen los derechos de migrantes. A nivel internacional, se trata esencialmente de instrumentos de la ONU. A nivel regional, el marco normativo incluye principalmente los convenios y acuerdos celebrados en el marco de la Unión Europea o de instrumentos de la Liga Árabe y de la Unión del Magreb. Marruecos también ha firmado algunos acuerdos bilaterales en materia de trabajo y seguridad social, con el objetivo de proteger a sus nacionales residentes en el exterior.

Marruecos ha ratificado la mayoría de las convenciones internacionales relativas a los derechos humanos, así como las relacionadas con los refugiados. En su calidad de miembro de diversas Organizaciones internacionales, ha ratificado también 62 convenios de la OIT que se aplican tanto a los nacionales como a los trabajadores extranjeros en Marruecos, lo que hemos mencionado anteriormente.

Marruecos ha firmado acuerdos en materia de migración con muchos países con el objetivo de proteger a los trabajadores marroquíes en el extranjero y para establecer las condiciones de contratación, trabajo y desplazamiento. También son acuerdos que garantizan la estabilidad a los trabajadores migrantes y protegen sus bienes en el país.

En el caso de Marruecos la firma de estos acuerdos fue en su mayoría con países europeos (Francia, Alemania, Bélgica, Holanda, España, Italia, etc.), con los Estados del Magreb, con otros países

\footnotetext{
${ }^{27}$ Así se precisa en el Projetd'appui du Système des Nations Unies à la Stratégie Nationale d'Immigration et d'Asile,Système des Nations unies auMaroc, 14 de diciembre de 2015 -http://www.un.org.ma/spip.php?article2314-.

${ }^{28} \mathrm{Si}$ en el siglo XX la política marroquí a nivel económico y de cooperación internacional estaba orientada casi exclusivamente hacia Europa, en los últimos años Mohamed
}

árabes y con países de África ${ }^{28}$. Con respecto a las relaciones con los países de África subsahariana Marruecos ha hecho un progreso significativo en las áreas de colaboración, con programas de intercambio educativo o acuerdos comerciales y en términos de la migración.

\subsection{El proceso de regularización: buena} iniciativa como confirmación de la nueva política de Marruecos en el ámbito de la inmigración irregular

Marruecos, tradicionalmente un país de emigrantes, se ha convertido en receptor de la emigración subsahariana e, inclusive, de inmigrantes procedentes de Europa. Dado el grave problema que esta situación representa para el Estado, era necesaria la elaboración de una política global sobre la cuestión migratoria tras registrarse un considerable aumento de emigrantes subsaharianos y europeos.

En este sentido, Mohamed VI insistió en la necesidad de proceder a la regularización de la situación de estas personas en materia de residencia y las actividades que ejercen, del mismo modo que los emigrantes regulares de otras nacionalidades, incluidos los subsaharianos.

Por otra parte, el Consejo Nacional de Derechos Humanos -CNDH (2013) consideró en un informe presentado al soberano que es urgente una nueva política para tratar los graves problemas derivados de la migración, que rompa con las prácticas actuales con los inmigrantes procedentes de otros países y los establecidos en Marruecos, procedentes principalmente de países subsaharianos.

Tras la publicación del Informe del CNDH, el Gobierno marroquí anunció su voluntad de poner en marcha una nueva política migratoria. Marruecos, en una iniciativa sin precedentes,

VI está tratando de diversificar sus socios económicos y orientándose hacia los países del Golfo (que invierten cada vez más en Marruecos), China y el continente africano en general. En la última gira de rey Mohamed VI a muchos países africanos ha tenido varios aspectos positivos a la cuestión del Sahara y ganó grandes proyectos económicos en la región. 
aprobó la regularización extraordinaria de inmigrantes que viven y trabajan en el país.

El proceso de regulación se inició el 1 de enero de 2014 y duró hasta el 31 de diciembre del mismo año. Según estimaciones oficiales se beneficiaron de estas medidas unos 15.000 subsaharianos, además de varios miles de extranjeros de otras nacionalidades, entre ellos centenares de españoles, que ocupan trabajos en la enseñanza privada, la construcción, los servicios, la hostelería, etc. Paralelamente se van a atender alrededor de 800 solicitudes de asilo y refugio avalados por la oficina de la ONU en Rabat.

La larga duración del proceso de implantación de la valiente apuesta marroquí en relación con el número de beneficiados, se explica, fundamentalmente, por que se desarrollará en un entorno y un contexto regional e internacional convulso y de gran complejidad, no sólo en lo que atañe al hecho migratorio en sí, sino debido también a la agitación política que se vive en todo el área mediterránea, en el Sahel y en África subsahariana. Debe considerarse también que el desarrollo de estas medidas tendrá numerosas repercusiones sociales, políticas y mediáticas en los países de las dos orillas del Mediterráneo.

En referencia al proceso de regularización, los últimos datos del Departamento de Anis Birrou (Ministro a cargo de los marroquíes residentes en el extranjero y los asuntos de migración) muestran la regularización de más de 18.000 migrantes en las 83 oficinas abiertas para este fin en diferentes regiones del Reino. Estos migrantes provienen de 112 países. El desglose por nacionalidades muestra que los solicitantes de la tarjeta procedentes de Senegal supusieron el $24,15 \%$ de las solicitudes. El segundo país de procedencia es Siria con un 19,2\%. Más tarde vienen Nigeria $(8,71 \%)$, Costa de Marfil (8,35\%), Guinea (5\%), Mali (4\%), Camerún (4\%), Filipinas (3\%), República Democrática del Congo (3\%). Otros detalles provenientes de la misma fuente señalan que 12 prefecturas y provincias absorbieron el $82 \%$ del total de solicitudes. Se trata en concreto de Rabat (6.932), Hay Hassani (2.824), Fez (2.520), OujdaAngad (2.204), Tánger-Asilah (1.955), Ain Sebaa
Hay Mohammadi (1.447), Casablanca-Anfa (1.063) Sale (1.005), Marrakech (887), Laayoune (688), Oued Ed-Dahab (661) y Inezgane Ait Melloul (465) (Saad, 2016).

Los criterios para solicitar la regularización fueron criticados por las organizaciones de derechos humanos alegando que añadían más obstáculos a los trámites en este tema. Entre estos requisitos, recogidos en el siguiente cuadro, se contemplaban: la residencia en Marruecos durante 5 años, las razones humanitarias o de enfermedad y 2 años de matrimonio con nacional marroquí.

A los seis meses de su inicio, la operación recibió más críticas de diversas organizaciones, denunciando que según cifras oficiales del mes de junio de 2016, solamente se resolvieron favorablemente 2.812 solicitudes de 16.000 presentadas. A finales de junio de 2014 se puso en marcha la Comisión Nacional de Seguimiento y Recurso con el fin de supervisar el proceso de regularización para mejorar su desarrollo y al mismo tiempo reexaminar aquellas solicitudes que fueron denegadas. La puesta en marcha de esta Comisión, así como la presión ejercida por las organizaciones de la sociedad civil hicieron que se mejorasen algunos aspectos, incrementándose el porcentaje de reconocimiento. A 2 de diciembre de 2014 , de 22.917 solicitudes presentadas se aceptaron positivamente el 46\% (10.603).

En febrero de 2015, el Ministro Delegado de Interior anunció que 17.916 solicitudes de un total de 27.332 fueron resueltas favorablemente, la mayoría de mujeres. Según el Ministro todas las solicitudes presentadas por mujeres y niños habrían sido resueltas favorablemente. Un total de 116 nacionalidades se habrían beneficiado de este proceso entre las cuales la más numerosa fue la senegalesa (Comisión Española de ayuda al refugiado - CEAR, 2015).

De hecho, a pesar de los signos positivos de la nueva política de migración marroquí, las organizaciones de la sociedad civil apuntan a la persistencia de los abusos, la violencia y el trato degradante de la policía marroquí contra los migrantes irregulares, especialmente en las afueras de Rabat, Oujda, Nador, Ceuta y Melilla. Así 
que el fin del proceso vino acompañado de una fuerte represión y persecución por parte de las autoridades marroquíes hacia las personas migrantes "no regularizadas".

\begin{tabular}{|c|c|}
\hline \multicolumn{2}{|c|}{ Proceso de regularización } \\
\hline Senegal & 6.600 \\
\hline Siria & 5.250 \\
\hline Nigeria & 2.380 \\
\hline Costa de Marfil & 2.281 \\
\hline Otras nacionalidades & 1.405 \\
\hline Total & 17.816 \\
\hline
\end{tabular}

Fuente: $\mathrm{CNDH}$ et déclaration de $\mathrm{Mr}$ le Ministre des affaires migratoires devant la chambre des représentants en date du 2 décembre 2014.

El 10 de febrero de 2015, las fuerzas de seguridad auxiliares marroquíes (en adelante 'FSA') desalojaron de forma violenta los campamentos en el monte Gurugu cerca de la frontera con Melilla. Estas redadas se repitieron en los días posteriores al 13 de febrero extendiéndose a la ciudad de Nador y alrededores. Según señalaron organizaciones de la sociedad civil como GADEM (Grupo Antiracista de acompañamiento y Defensa de los Extranjeros y Migrantes) y CCSM (Colectivo de Migrantes Subsaharianos en Marruecos), al menos 1.200 personas fueron detenidas arbitrariamente en la región de Nador y al menos 800 de ellas fueron conducidas a centros de retención improvisados en 18 ciudades diferentes del Sur de Marruecos, a donde fueron trasladadas en autobuses. Entre ellas se encontraban menores de edad, mujeres embarazadas, solicitantes de asilo y personas que habían presentado su solicitud al proceso de regularización pero no habían recibido respuesta 29 .

\section{CONCLUSIÓN}

Llegamos a la conclusión de todo lo que hemos mencionado que Marruecos ha experimentado

29 En un comunicado del AMDH y GADEM (Grupo Antiracista de acompañamiento y Defensa de los Extranjeros y Migrantes) se denuncian las violaciones y las detenciones de migrantes cometidas el 16 de febrero 2015. ACNUR todo tipo de migración: interna e internacional, voluntaria e involuntaria, individual y colectiva, legal e ilegal. Ya no sólo constituyen una región de emigración, inmigración y tránsito, sino también de destino de muchos inmigrantes.

Por eso Marruecos fue elegido como el mejor modelo entre los países de la región (el Magreb) en términos de abordar el fenómeno de la migración en todos sus aspectos, a pesar de una serie de deficiencias y dificultades. La aprobación de la Ley $n^{\circ}$ 02-03 en 2003 sobre Entrada y estancia de extranjeros en Marruecos, emigración e inmigración irregulares puso fin a un vacío jurídico en la materia. Con ese instrumento normativo Marruecos se dotó de un marco jurídico moderno, conforme a sus compromisos internacionales, y dio respuesta a una nueva situación, en la que Marruecos se convierte en un lugar de tránsito y destino cada vez más privilegiado de inmigrantes procedentes de otros países del Magreb, subsaharianos e incluso europeos.

También Marruecos es el primer país magrebí en iniciar el proceso de regularización en principio de 2016; lo que debe verse como una buena iniciativa para confirmar la nueva política del país en el ámbito de la inmigración irregular. La iniciativa de las autoridades marroquíes, saludada por las organizaciones de la sociedad civil, es única entre los países de la zona, mostrando el camino a sus vecinos norteafricanos $\mathrm{y}$, de paso, también la España. Con ella han mostrado habilidad política, en primer lugar para con sus ciudadanos, sobre todo los que formamos parte de la diáspora, en segundo lugar con los propios inmigrantes de terceros países que optan por instalarse en Marruecos y en tercer lugar, con los Estados amigos, socios y con todos los que comparten estos problemas, particularmente la Unión Europea, los países subsaharianos y del África occidental.

Marruecos en un mensaje enviado a Amnistía Internacional confirmó que mediante contacto directo con ONG's había identificado 14 solicitantes de asilo entre los detenidos. 


\section{BIBLIOGRAFÍA}

Aboussi, M. (2011). La nueva política migratoria marroquí ante retos de transnacionalismo y codesarrollo. Revista de Estudios Internacionales Mediterráneos, (10).

Barros, L.; Lahlou, M.; Escoffier, C.; Pumares, P. and Ruspini, P. (2002). L'immigration Irregulière Subsaharienne à Travers et Vers le Maroc. Geneva, Italia: ILO.

Belguendouz, A. (2009). Le Maroc et I'Im (é)migration, Quelles politiques, Quelles institutions, Quelle citoyenneté. Rabat, Maroc: Imprimerie Beni Snassen.

Charef. M. (2014). Regularización de inmigrantes y nueva política de inmigración en Marruecos. Madrid, España: Fundación Ciudadanía y Valores

Chigueur, M. (1997). L'émigration marocaine vers l'Europe: fluctuation et perspective. Cahier du Centre d'Etude sur les Mouvement Migratoire Maghrébins (5).

Chaudier, J. (2013). Le Maroc compte 10 fois moins d'étrangers que la France, Yabiladi. Recuperado de https://www.yabiladi.com/articles/detail s/19770/maroc-compte-fois-moins-detrangers.html.

Khachani, M. (2006). La emigración subsahariana: Marruecos como espacio de tránsito". Documentos CIDOB, Serie Migraciones (10).
Khadija, E.M. (2004). La nouvelle Loi sur l'immigration: des apports et aussi des limites". Magazine marocain, Homme (mars).

Khadija, E.M. (2004). Les migrants et leurs droits au Maghreb avec une référence spéciale à la Convention sur la protection des droits de tous les travailleurs migrants. Rapports par pays sur la ratification de la Convention des Nations Unies sur les droits des migrants (9).

López, A.M. (2004). Las dinámicas migratorias en el Marruecos actual. Nova Africa (14).

Khrouz, N.; Ouardi, A.; Rachidi, H. (2009). Le cadre juridique relatif à la condition des étrangersauregard de l'application du pouvoir exécutif et de l'interprétation du juge. Janvier: Maroc: Gadem.

Khrouz,N. (2013). La pratique judiciaire marocaine $d u$ droit des étrangers. praxéologie juridique et politique relative aux droits des étrangers subsahariens au Maroc. Thèse de science politique sous la direction de DUPRET B., Science politique, laboratoire PACTE - Université de Grenoble, Grenoble.

Perrin, D. (2008). L'étrangerrendu visible auMaghreb - La voieouverte à la transposition des politiques juridiques migratoires européennes. Revue ASYLON(S). 